Article

\title{
Anthropogenic factors affecting the vegetation dynamics in the arid Middle East
}

\author{
Iman Rousta 1,2, Haraldur Olafsson 3 , Hao Zhang 4, Md Moniruzzaman 5, Jaromir Krzyszczak 6,* \\ and Piotr Baranowski ${ }^{6}$ \\ 1 Department of Geography, Yazd University, Yazd 8915818411, Iran; irousta@yazd.ac.ir \\ 2 Institute for Atmospheric Sciences-Weather and Climate, University of Iceland and Icelandic \\ Meteorological Office (IMO), Bustadavegur 7, IS-108 Reykjavik, Iceland \\ 3 Institute for Atmospheric Sciences-Weather and Climate and Department of Physics, University of Iceland \\ and Icelandic Meteorological Office (IMO), Bustadavegur 7, IS-108 Reykjavik, Iceland, Email: \\ haraldur@vedur.is \\ 4 Department of Environmental Science and Engineering Jiangwan Campus, Fudan University, 2005 Songhu \\ Road,Yangpu District Shanghai 200438, China; zhokzhok@163.com \\ 5 ASICT Division, Bangladesh Agricultural Research Institute, Gazipur-1701, Bangladesh; \\ moniruzzaman1313ku@gmail.com \\ 6 Institute of Agrophysics, Polish Academy of Sciences, Doświadczalna 4, 20-290 Lublin, Poland; \\ j.krzyszczak@ipan.lublin.pl, p.baranowski@ipan.lublin.pl \\ * Corresponding author: Jaromir Krzyszczak, e-mail: j.krzyszczak@ipan.lublin.pl; ORCID ID: 0000-0002- \\ 9235-8119, phone: (+48) 817445061, fax: (+48) 81744506
}

\begin{abstract}
The spatiotemporal variability of vegetation in the Middle East was investigated for the period 2001-2019 using the Moderate Resolution Imaging Spectroradiometer (MODIS) 16-day/500 m composites of the Normalized Difference Vegetation Index (NDVI; MOD13A1). The results reveal a strong increase in the NDVI coverage in the Middle East during the study period ( $R=0.75$, $p$-value $=0.05)$. In Egypt, the annual coverage exhibits the strongest positive trend $(R=0.99$, $p$-value $=0.05)$. In Turkey, both the vegetation coverage and density increased from 2001 to 2019, which can be attributed to the construction of some of the biggest dams in the Middle East, such as the Atatürk and Ilisu dams. Significant increases in the annual coverage and maximum and average NDVI in Saudi Arabia are due to farming in the northern part of the country for which groundwater and desalinated seawater are used. The results of this study suggest that the main factors affecting the vegetation coverage in the Middle East are governmental policies. These policies can have a positive effect on the vegetation coverage in some countries such as Egypt, Saudi Arabia, Qatar, Kuwait, Iran, and Turkey.
\end{abstract}

Keywords: Middle East; Moderate Resolution Imaging Spectroradiometer; Normalized Difference Vegetation Index; time series analysis; governmental policy

\section{Introduction}

In the 21st century, global climate change (GCC) studies have focused on the vegetation dynamics at local, regional, continental, and global scales. Vegetation is the basis of all living beings and plays an essential role in GCC [1-4]. The GCC and its impact on land-dwelling ecosystems and the global environment have triggered public concern in the last few decades [5-8]. Field surveys can be used to obtain accurate ground data related to vegetation variations and their indicators; however, in situ observations are expensive, time-consuming, laborious, spatially limited, and are rapidly becoming outdated [9-12]. After the introduction of remote sensing (RS), satellite-based remotely sensed data have been progressively used to monitor the vegetation dynamics; they are dominating because of the contiguous long-term spatiotemporal variability, free availability, large geographic coverage, and frequent and near-real-time workability [13-25]. 
The Moderate Resolution Imaging Spectroradiometer (MODIS) is a spaceborne imaging sensor aboard the NASA Terra satellite, which produces ecological indicators that are available on a global scale [26]. MODIS has a high temporal (daily to annual) and a varying spatial (250 $\mathrm{m}$ to $1 \mathrm{~km}$ ) resolution. The MODIS is used to track environmental characteristics such as land use, food security, environmental sustainability, disruption, and climate change [2]. The vegetation index (VI) is used as an indicator of vegetation variability, and is a sensitive spectral signature of vegetation phenology. It combines different spectral bands of RS data, which can be used to quantify the vegetation conditions $[27,28]$, growth status, biophysical variables (e.g., Leaf Area Index LAI, productivity, and vegetation cover types) [29-31]. Among all VIs, the Normalized Difference Vegetation Index (NDVI) is the most well-known and widely used. The NDVI is based on red and near-infrared (NIR) spectra [32, 33]. The NDVI varies from -1.0 to +1.0 , where positive values (following an increasing trend) denote healthy vegetation conditions. However, zero and negative values indicate non-vegetation elements such as clouds, dust, water, rock, and water vapor [34]. The mesophyll structure of healthy leaves influences an NIR spectrum signal, because it strongly imbibes photosynthetically active radiation [23]. The NDVI is used to monitor the green vegetation status and land cover, which comprises unstressed vegetation [15], and to evaluate ecological responses to environmental changes [30, 35, 36]. The NDVI correlates with vegetation functions, such as the biomass [37, 38], primary productivity [39, 40], and LAI, and can be used to investigate land-dwelling vegetation and climate relationships [33, 41-44].

The NDVI index has been applied to many scientific studies worldwide. Bagherzadeh et al. confirmed the utility of the NDVI to express the vegetation variability under semiarid climate conditions [45]. The results of several studies utilizing NDVI time series revealed the recent increase in the vegetation efficiency in karst regions [11,46-48], indicating that the NDVI of each vegetation type is variable. The long-term NDVI can be used to indicate vegetation trends $[45,49,50]$ and monitor local, regional, and global trends as well as vegetation inconsistencies [51, 52]. Evans reported that the viable rainfed agricultural land area has decreased by $>170,000 \mathrm{~km}^{2}$ until the end of the 20th century in the Middle East (ME) due to climate change [53].

The ME comprises both arid and semiarid regions, which are considered as the hottest places on earth, such as the Saudi Arabia deserts and Dasht-E-Lut in Iran. On the other hand, the region suffers from severe droughts and some of the longest wars, such as those in Syria, Yemen, and Iraq. Therefore, the vegetation in this region is affected by many anthropogenic and natural phenomena. Few studies have focused on the vegetation dynamics in the ME. Therefore, the aim of this study was to investigate the trends in vegetation productivity and coverage in the ME using satellite-derived information. An attempt was made to measure the long-term spatiotemporal variability of the vegetation coverage using time series analysis and correlation assessment in ME countries. The results of this study can be used by policymakers in the ME to closely examine the vegetation dynamics and their variations in each region and country. Studying the NDVI dynamics and their relationship with vegetation growth, and monitoring in this region is very important for ensuring agricultural, hydroecological, and environmental sustainability, and food security; it is also necessary for formulating effective intergovernmental policies.

\section{Materials and Methods}

\subsection{Study area}

The use of "Middle East" first arose in the early years of the present century, referring to the area surrounding the Persian Gulf. According to Fisher, it is the logical intermediate delineation between the Mediterranean "Near East" and "Far East" [54]. The region includes Bahrain, Egypt, Palestine, Iran, Iraq, Israel, Jordan, Kuwait, Lebanon, Oman, Qatar, Saudi Arabia, Syrian, Turkey, the United Arab Emirates (UAE), and Yemen $[55,56]$. The region is located between $12^{\circ} \mathrm{N}$ and $42^{\circ} \mathrm{N}$ and $24^{\circ} \mathrm{E}$ and $63^{\circ} \mathrm{E}$, covering a total area of $\sim 7.2$ million $\mathrm{km}^{2}$ and including a population of $\sim 420$ million people (Figure 1 \& Table 1). During the 1990s, the economic development of ME region grew at $50 \%$ of the rate of other developing countries [55]. 


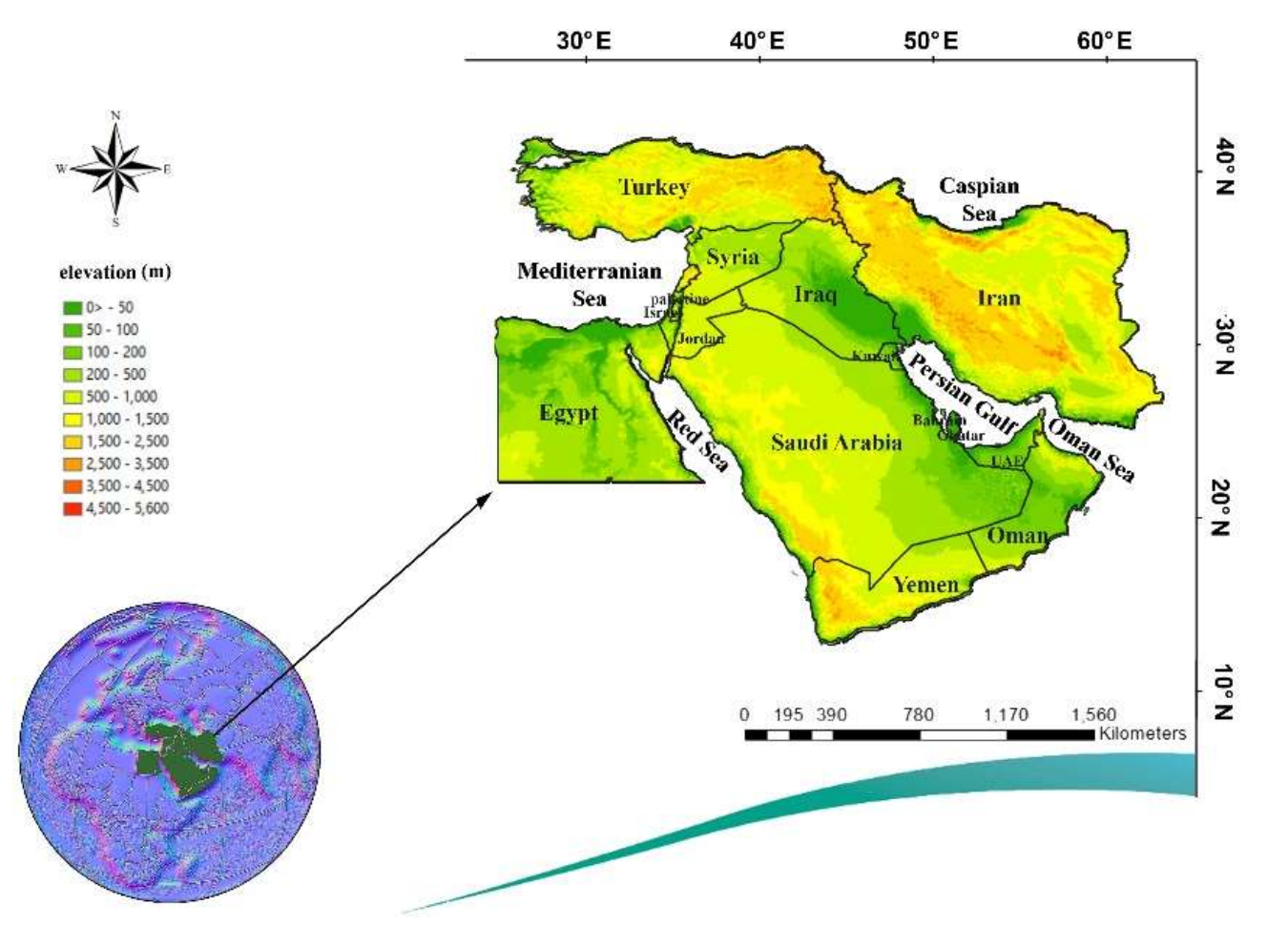

Figure 1. Map presenting the study area (the Middle East) including an elevation profile.

Table 1. Population and area of Middle East countries.

\begin{tabular}{cccc}
\hline Country name & Middle East Population & Population $\mathbf{( \% )}$ & Area $\left.\mathbf{( k m}^{2}\right)$ \\
\hline Egypt & $90,253,760$ & 21.5 & $1,010,407$ \\
Iran & $82,467,049$ & 19.6 & $1,648,195$ \\
Turkey & $78,214,000$ & 18.6 & 783,562 \\
Iraq & $36,575,000$ & 8.7 & 438,317 \\
Saudi Arabia & $31,521,000$ & 7.6 & $2,149,690$ \\
Yemen & $26,745,000$ & 6.4 & 527,970 \\
Syria & $23,270,000$ & 5.5 & 185,180 \\
Jordan & $10,248,069$ & 2.4 & 92,300 \\
UAE & $9,154,000$ & 2.2 & 82,880 \\
Israel & $8,547,000$ & 2.0 & 20,770 \\
Lebanon & $6,185,000$ & 1.5 & 10,452 \\
Palestine & $4,816,503$ & 1.1 & 6,220 \\
Oman & $4,181,000$ & 1.0 & 212,460 \\
Kuwait & $4,161,000$ & 1.0 & 17,820 \\
Qatar & $2,113,000$ & 0.5 & 11,437 \\
Bahrain & $1,781,000$ & 0.4 & 665 \\
\hline Total & $\mathbf{4 2 0 , 2 3 2 , 3 8 1}$ & $\mathbf{1 0 0}$ & $\mathbf{7 , 1 9 8 , 3 2 5}$ \\
\hline
\end{tabular}




\subsection{Methods}

The MODIS NDVI 16-days/500 m (MOD13A1) product was used in the current study. The Shuttle Radar Topography Mission (SRTM) digital elevation data with a resolution of 1 arc-second $(\sim 30 \mathrm{~m})$ were utilized in this study to provide an elevation map of the study area [57].

\subsubsection{Normalized Difference Vegetation Index}

The NDVI has become the most common and widely used index to investigate the vegetation status and is derived from the production variety and LAI [58-61]. In the modern era, many scientists used the NDVI in various studies relating to vegetation class, vegetation phenology, continental land cover mapping, chlorophyll content, land use/land cover changes, and water stress [21, 28, 33, 62 66]. The NDVI provides information about the inner mesophyll of healthy green leaves that highly reflects near-infrared (NIR) radiation, whereas leaf chlorophyll and other pigments assimilate a huge proportion of the visible (VIS) radiation. In the case of unhealthy vegetation the spectrum that reflects the inner leaf composition is reversed $[16,58]$. The NDVI is calculated as follows:

$$
N D V I=\frac{N I R-R E D}{N I R+R E D}
$$

The NDVI index ranges from -1 to +1 [67]. In the present research, 437 images from the Terra MODIS 16-day composite NDVI with $500 \mathrm{~m}$ resolution (MOD13A1.006_500m_16_days_NDVI) for 2001-2019 were downloaded using the Application for Extracting and Exploring Analysis Ready Samples (Ag@EEARS) application platform (https://lpdaacsvc.cr.usgs.gov.appeears) [68]. To calculate the seasonal and yearly vegetation coverage, the NDVI was divided into seven categories $(0.2-0.3,0.3-$ $0.4,0.4-0.5,0.5-0.6,0.6-0.7,0.7-0.8$, and $>0.8)$ and the arithmetic mean was calculated for each pixel using the following equations:

$$
\begin{aligned}
& \text { Winter vegetation coverage }=\frac{\left.\sum \text { (image } 353 \text { to image } 065\right)}{6}, \\
& \text { Spring vegetation coverage }=\frac{\sum(\text { image } 081 \text { to image } 161)}{6}, \\
& \text { Summer vegetation coverage }=\frac{\left.\sum \text { (image } 177 \text { to image } 257\right)}{6}, \\
& \text { Fall vegetation coverage }=\frac{\left.\sum \text { (image } 273 \text { to image } 337\right)}{5}, \\
& \text { Yearly vegetation coverage }=\frac{\sum(\text { image } 017 \text { to image } 001)}{23} .
\end{aligned}
$$

\subsubsection{Anomaly algorithm and interpretation}

The anomaly is an indicator calculated on the basis of the selected periods of time and shows how the parameter for a particular time period compares with the entire period $[33,69]$ by indicating how many standard deviations away a given observation is from the mean. Conceptually, the calculation of the anomaly is equivalent to the calculation of the Z-score used in statistics and is formulated as follows:

$$
Z i j=\frac{X i j-U i j}{\sigma i j}
$$

where $Z i j$ is the anomaly of the $i$-th time period at the $j$-th time-scale, $X i j$ is the parameter (as NDVI) sum for the $i$-th time period at the $j$-th time-scale, and $U i j$ and $\sigma i j$ are the long-term mean and standard deviation, respectively, connected with the $i$-th time period at the $j$-th time-scale [70]. A positive anomaly indicates that the values of the investigated quantity are greater than the mean, whereas negative values indicate that the values of the investigated quantity are lower than mean. Typically, 
data with an anomaly score exceeding an arbitrary threshold of 2 is flagged as abnormal, while data with an anomaly $<|0.5|$ can be treated as typical and is indicated in the figures as "normal area".

\subsubsection{Linear regression}

In this study, linear regression was used to define the correlations at a significance level of 0.05 . Therefore, in this study, "significant" refers to a significance level of 0.05 . It is a statistical method to model the relationship by fitting a linear equation between two variables, where one is as an explanatory variable and the other is a dependent variable [71]. The linear regression model can be described as follows:

$$
y_{i}=a+b x_{i}
$$

where $a$ and $b$ are the regression coefficients. The coefficients in Eq. (8) can be obtained for the given parameters $x_{i}$ and $y_{i}$.

\section{Results}

\subsection{NDVI changes}

Figure 2 shows the average vegetation coverage (NDVI > 0.2) in the ME during the study period. The vegetation coverage gradually increases from January ( $12 \%$ of the whole study area) and peaks in late April. Consequently, $21 \%$ of the area is covered by vegetation $\left(\sim 1,519,200 \mathrm{~km}^{2}\right)$. Starting in May, the vegetation cover gradually decreases and reaches its minimum annual value in the warm season by the end of September ( $14 \%$ vegetation coverage; $\sim 1$ million $\left.\mathrm{km}^{2}\right)$. The vegetation cover gradually increases from the first of October to mid-November and, then, decreases. Accordingly, the primary growing season (GS) in the ME starts around January 1 and ends within the first ten days of May (Figure 2). Because the study area is large (extends to different northern latitudes) and the elevation significantly varies, it is difficult to generalize the data for the whole area. Spring is the greenest season. This greenness continues into the summer season until the end of June. Subsequently, the vegetation coverage decreases, primarily because of the scarcity of rain in the study area.

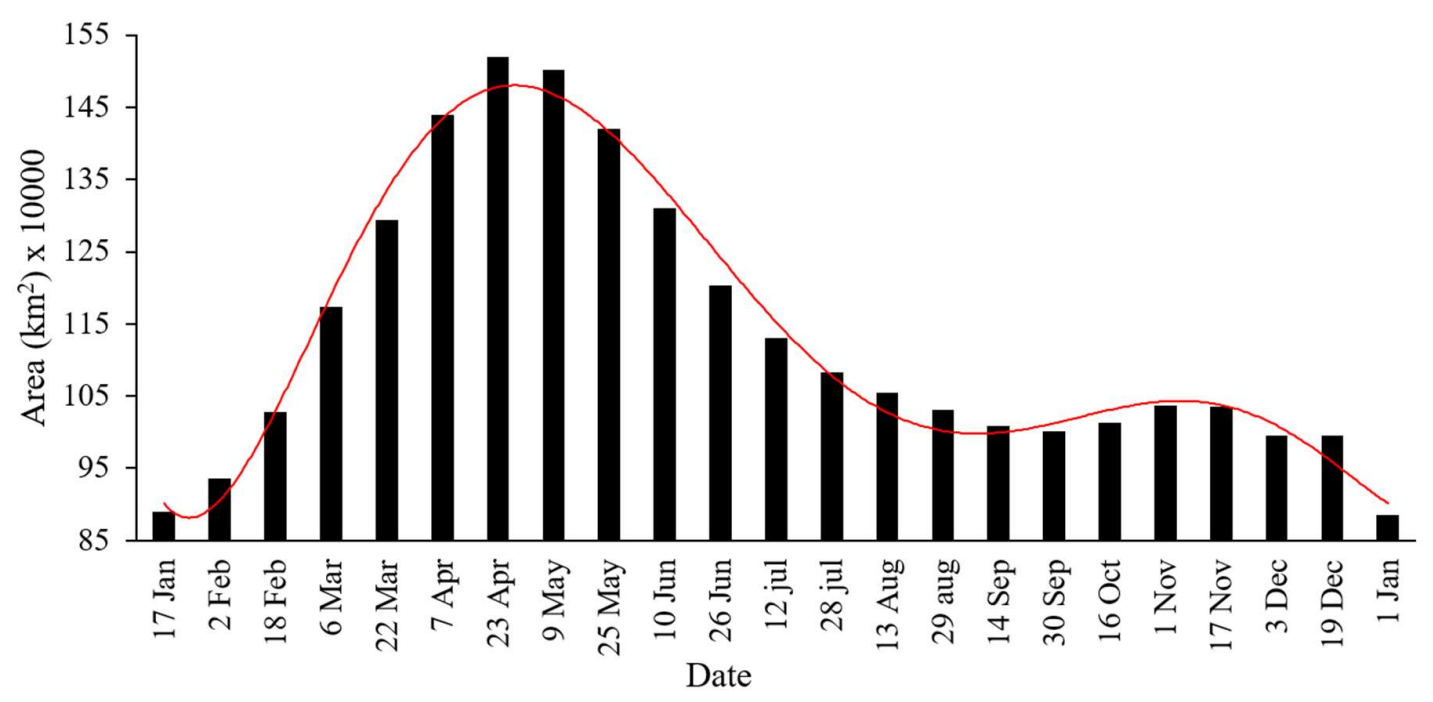

Figure 2. Average vegetation coverage in the Middle East during 2001-2019.

Figure 3 shows the annual average vegetation coverage in the ME based on all NDVI categories $(0.2-0.3,0.3-0.4,0.4-0.5,0.5-0.6,0.6-0.7,0.7-0.8$, and $>0.8)$ for the study period. A significant positive trend of the NDVI coverage in the study area can be observed in the period $2001-2019(R=0.75, p-$ 
value $=0.05$ ); however, a substantial interannual variability can also be detected. The years 2015, 2018, and 2019 exhibit the maximum coverage, accounting for 17\%, 18\%, and 20\% of the study area, respectively $\left(1.22,1.28\right.$, and 1.43 million $\mathrm{km}^{2}$, respectively), whereas the minimum vegetation coverage was observed in 2001, 2003, and 2008, accounting for $14 \%, 15 \%$, and $14 \%$ of the study area, respectively $\left(1.02,1.05\right.$, and 0.975 million $\mathrm{km}^{2}$, respectively).

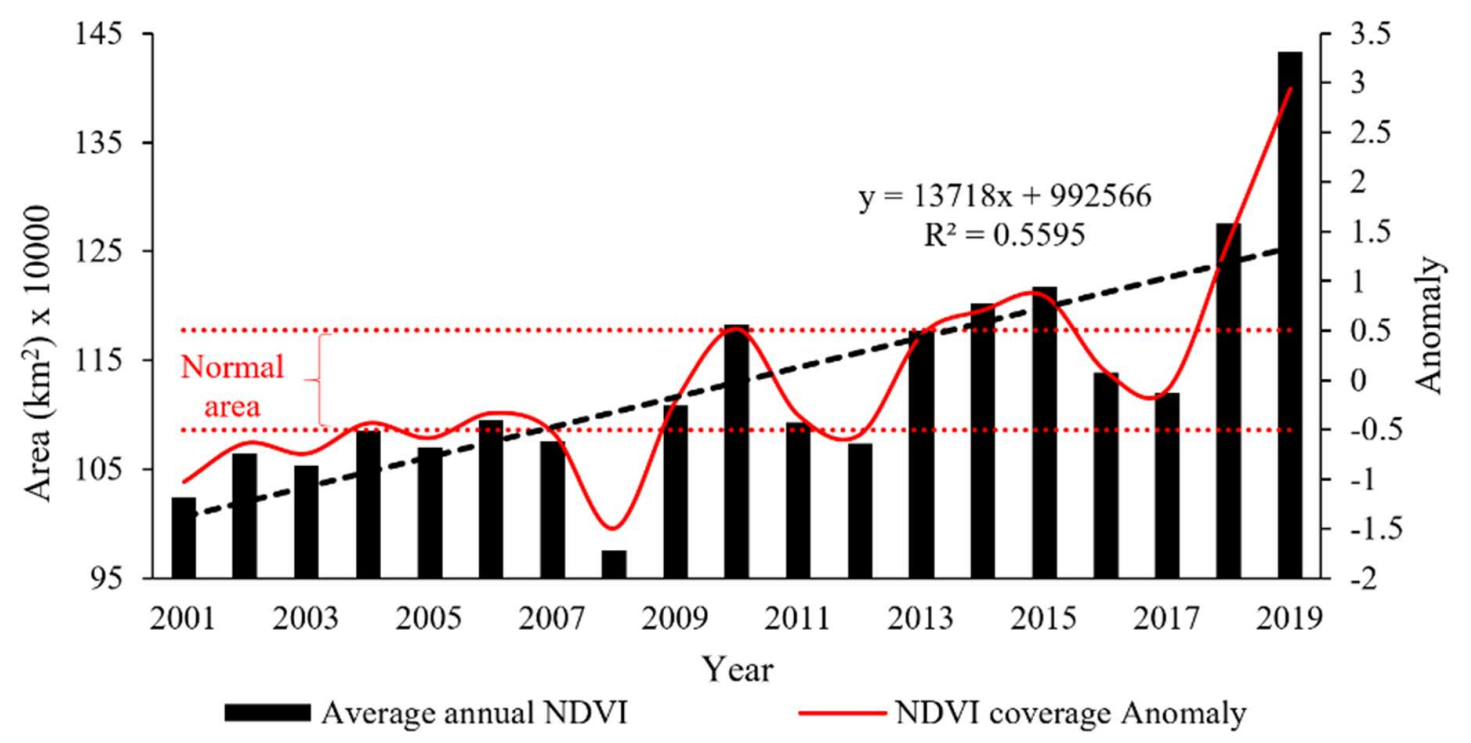

Figure 3. Average annual vegetation coverage in the Middle East during 2001-2019 (black bars), showing the linear trend line (black discontinuous line) supplemented by the Normalized Difference Vegetation Index (NDVI) coverage anomaly (red continuous line) and normal area (red dotted lines).

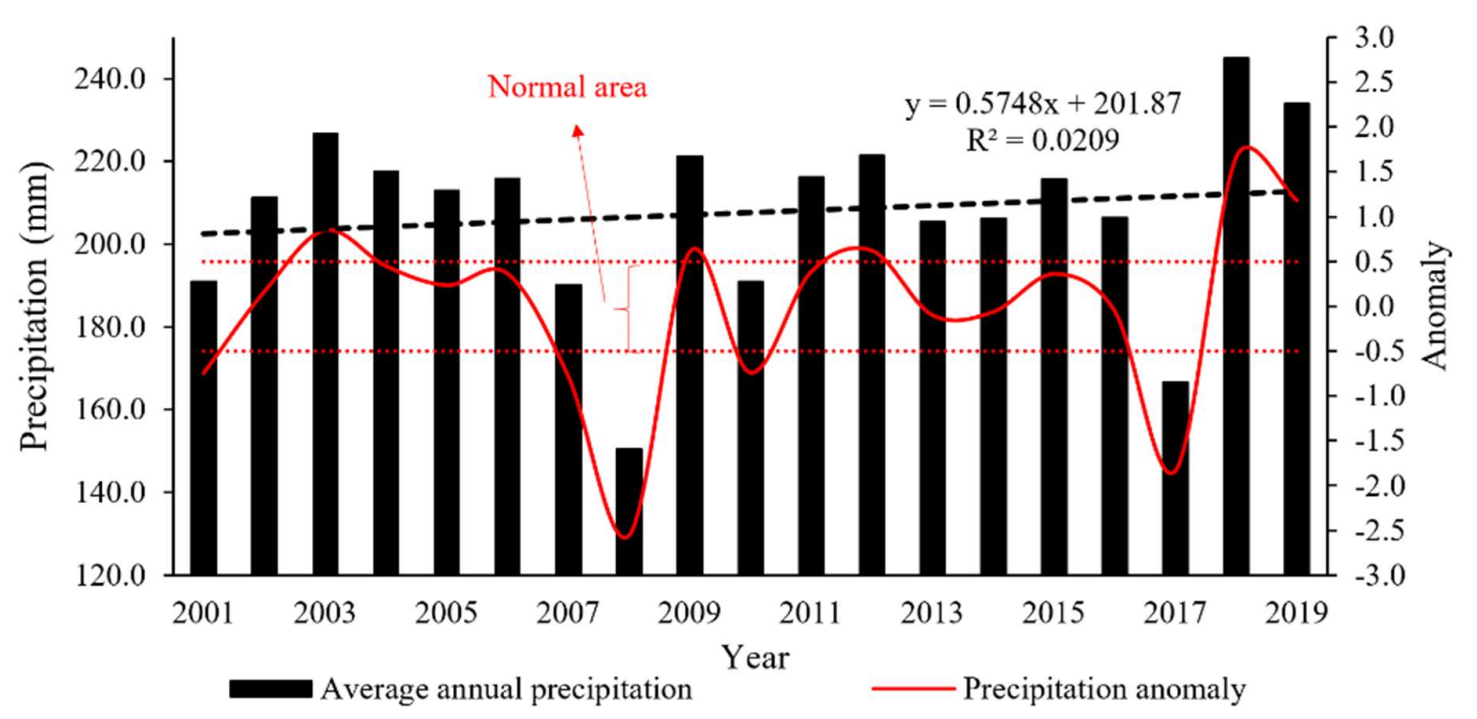

Figure 4. Total annual precipitation in the Middle East during 2001-2019 (black bars), with the linear trend line (black discontinuous line), precipitation anomaly (red continuous line), and normal area (red dotted lines).

Figure 4 shows the changes in the total annual precipitation in the ME during the study period. The trend line indicates that the precipitation insignificantly changes during the study period. Instead, a high interannual variability can be observed, which correlates with the interannual variability of the NDVI. This suggests that precipitation is one of the factors affecting the changes in the NDVI; however, it cannot explain the significant positive trend of the NDVI shown in Figure 3. 


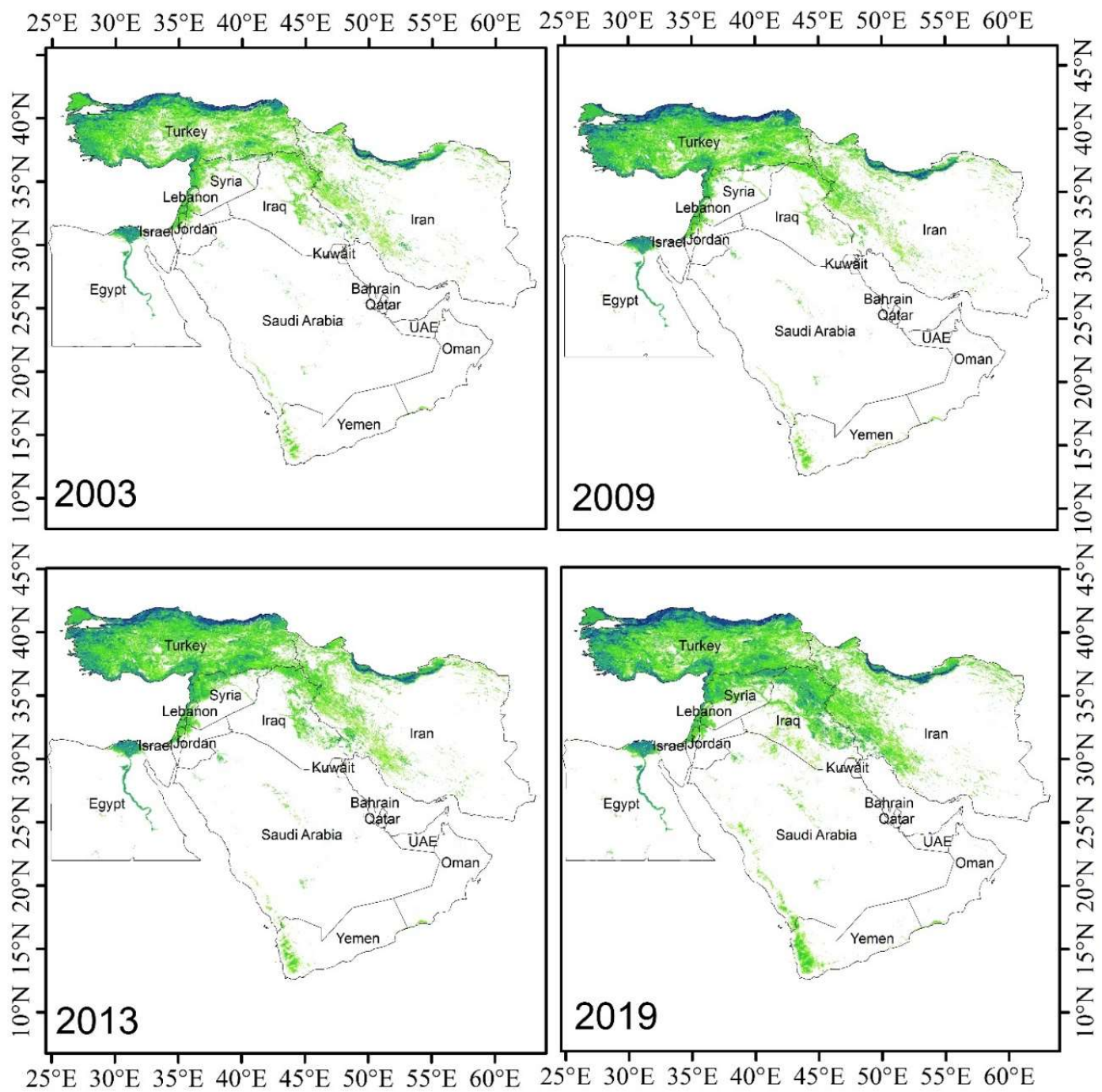

NDVI
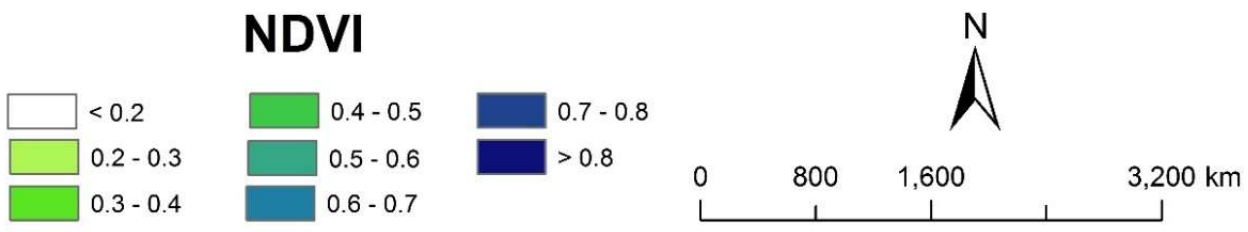

Figure 5. Maps of the Normalized Difference Vegetation Index (NDVI) for the study area for the chosen years (2003, 2009, 2013, and 2019).

Figure 5 shows the maps of the NDVI in the study area for four years $(2003,2009,2013$, and 2019). A large increase in the vegetation area can be observed on the border of Iran and Iraq, Iraq, and Saudi Arabia, and Israel, Lebanon, and Jordan; in the central part of Turkey; in the northern part of Syria; and in the western parts of Saudi Arabia and Yemen.

Figure 6 shows the time series of different NDVI categories for the ME from 2001 to 2019. A significant increasing trend ( $p$-value $=0.05$ ) can be observed in the NDVI category 0.3 to $>0.8$ and an insignificant increase can be detected in the NDVI category 0.2-0.3. In all categories, a trough can be observed in 2008, 2012, and 2017 and a ridge can be detected in 2010, 2015, 2018, and 2019. This indicates that the first group is the driest (less vegetation) and the second group is the greenest (dense vegetation) during the study period (Figure 6). 

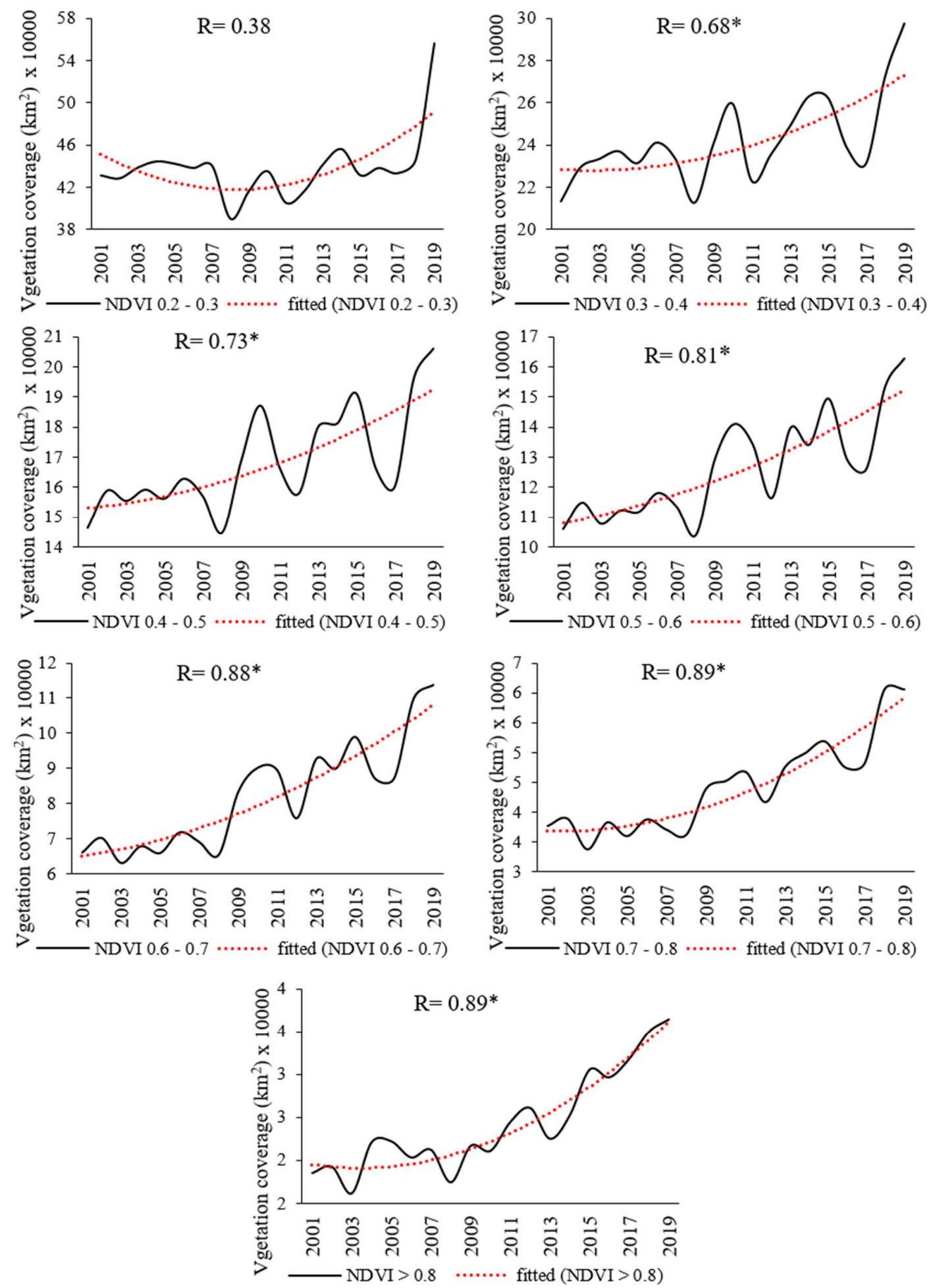

Figure 6. Average annual coverage $\left(\mathrm{km}^{2}\right)$ for different vegetation categories in the Middle East during 2001-2019. * denotes that the correlation is significant at $\mathrm{p}=0.05$.

Table 2 shows the NDVI trends in the ME for each 16-day MODIS image during the study period. A significant positive trend can be observed in all images, except for the images obtained on January 17. This reveals that the $\mathrm{ME}$ is becoming greener and the vegetation coverage increases in all months. The correlation coefficients obtained for August 13 and 29 and September 14 and 30 are higher than those determined in other months $(R=0.76,0.76,0.81$, and 0.83 , respectively). 
Table 2. Trend of the vegetation coverage determined with an interval of 16 days from MODIS images for the Middle East for the period 2001-2019.

\begin{tabular}{cc}
\hline Date & Correlation \\
\hline 1 Jan & $0.59^{*}$ \\
$17 \mathrm{Jan}$ & 0.35 \\
$2 \mathrm{Feb}$ & 0.41 \\
$18 \mathrm{Feb}$ & $0.48^{*}$ \\
$6 \mathrm{Mar}$ & 0.40 \\
$22 \mathrm{Mar}$ & $0.46^{*}$ \\
$7 \mathrm{Apr}$ & $0.57^{*}$ \\
$23 \mathrm{Apr}$ & $0.60^{*}$ \\
$9 \mathrm{May}$ & $0.62^{*}$ \\
$25 \mathrm{May}$ & $0.57^{*}$ \\
$10 \mathrm{Jun}$ & $0.56^{*}$ \\
$26 \mathrm{Jun}$ & $0.65^{*}$ \\
$12 \mathrm{Jul}$ & $0.67^{*}$ \\
$28 \mathrm{Jul}$ & $0.73^{*}$ \\
$13 \mathrm{Aug}$ & $0.76^{*}$ \\
$29 \mathrm{Aug}$ & $0.76^{*}$ \\
$14 \mathrm{Sep}$ & $0.81^{*}$ \\
$30 \mathrm{Sep}$ & $0.83^{*}$ \\
$16 \mathrm{Oct}$ & $0.69^{*}$ \\
1 Nov & $0.66^{*}$ \\
$17 \mathrm{Nov}$ & $0.67^{*}$ \\
3 Dec & $0.62^{*}$ \\
$19 \mathrm{Dec}$ & $0.62^{*}$ \\
\hline
\end{tabular}

* denotes a significant correlation at $\mathrm{p}=0.05$.

\subsection{Seasonal NDVI dynamics}

Figures 7 and 8 show the seasonal NDVI dynamics of the ME in the study period (2001-2019). Overall, vegetation covers $\sim 19.2 \%$ of the study area during the study period. In the study area, spring is the greenest season, followed by winter, fall, and summer, with vegetation coverage of $22.8 \%$, $20.2 \%, 17 \%$, and $16.8 \%$ of the study area, respectively. In all seasons, the densest vegetation coverage was observed in the coastal areas of the Caspian Sea in northern Iran, Black Sea in northern Turkey, Mediterranean Sea in western and southwestern Turkey, western Syria, Lebanon, Israel, Palestine, and Egypt or along large rivers such as the Nile. The driest countries in the ME are Qatar, Kuwait, the UAE, and Saudi Arabia, with vegetation coverage accounting for less than $1 \%$ of the total area of the country. Oman, Bahrain, Egypt, Jordan, and Yemen have vegetation coverage of 1\%, 2.7\%, 3.7\%, $3.9 \%$, and $4.3 \%$ of the whole ME, respectively (Figures $7-8$ and Table 3 ). 

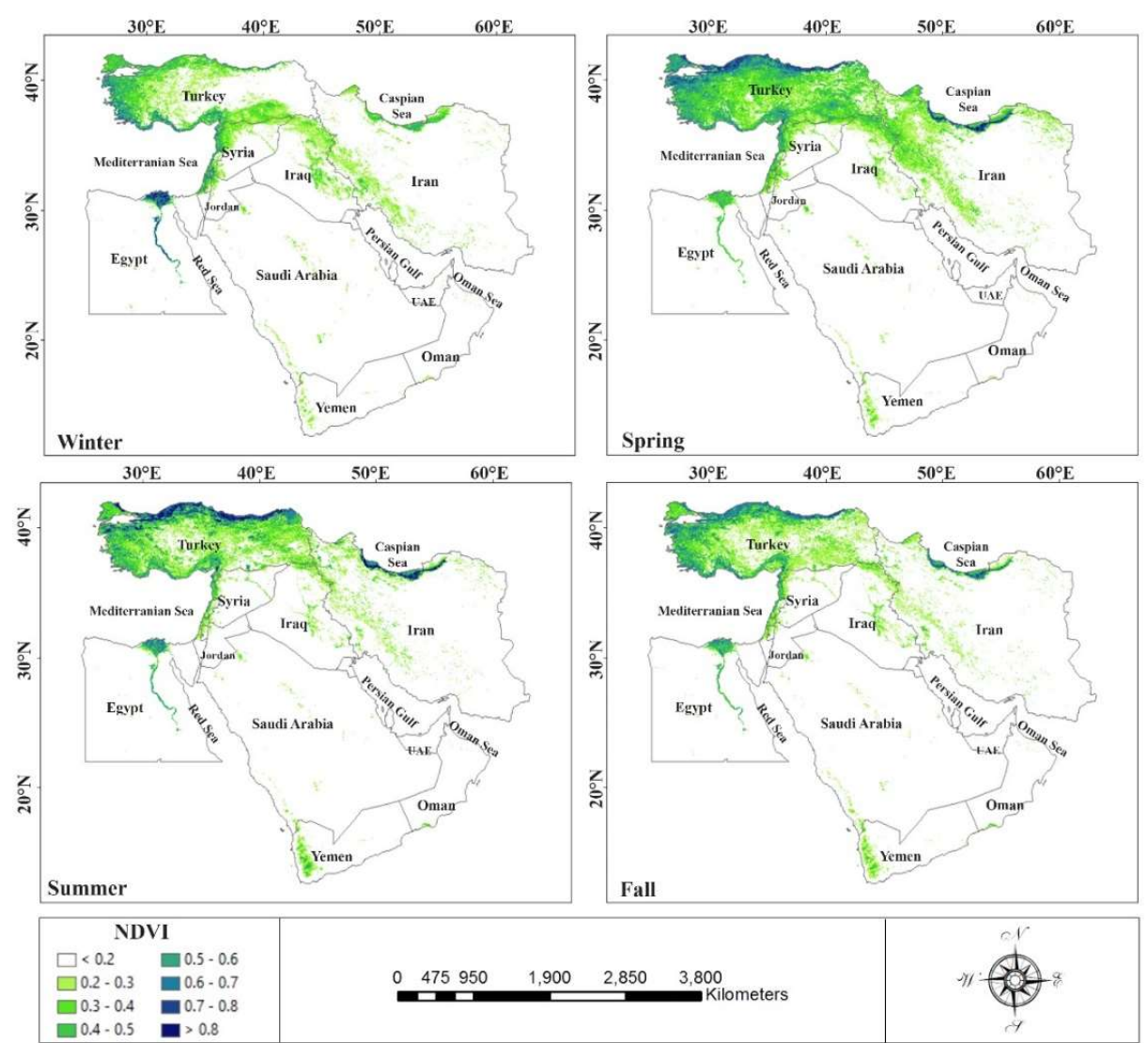

Figure 7. Seasonal Normalized Difference Vegetation Index (NDVI) average in the Middle East during 2001-2019.

Figure 8 shows the seasonal average vegetation coverage percentage for each country in the ME. In winter, Palestine, Lebanon, and Turkey are the greenest countries in the study area, with vegetation coverage of $76.9 \%, 67.6 \%$, and $54.2 \%$, respectively. In spring, Turkey, Lebanon, and Palestine are the greenest countries, with vegetation coverage of $93.8 \%, 77.7 \%$, and $67.2 \%$, respectively. In summer and fall, Turkey, Lebanon, and Palestine are the greenest, with vegetation coverage of $83.4 \%, 66.1 \%$, and $39.9 \%$ in summer and $73.7 \%, 66 \%$, and $47.7 \%$ in fall, , respectively. In all seasons, Qatar, UAE, Saudi Arabia, Kuwait, and Oman are the driest countries, with vegetation coverage $<1.2 \%$ (Figures 7-8 and Table 3).

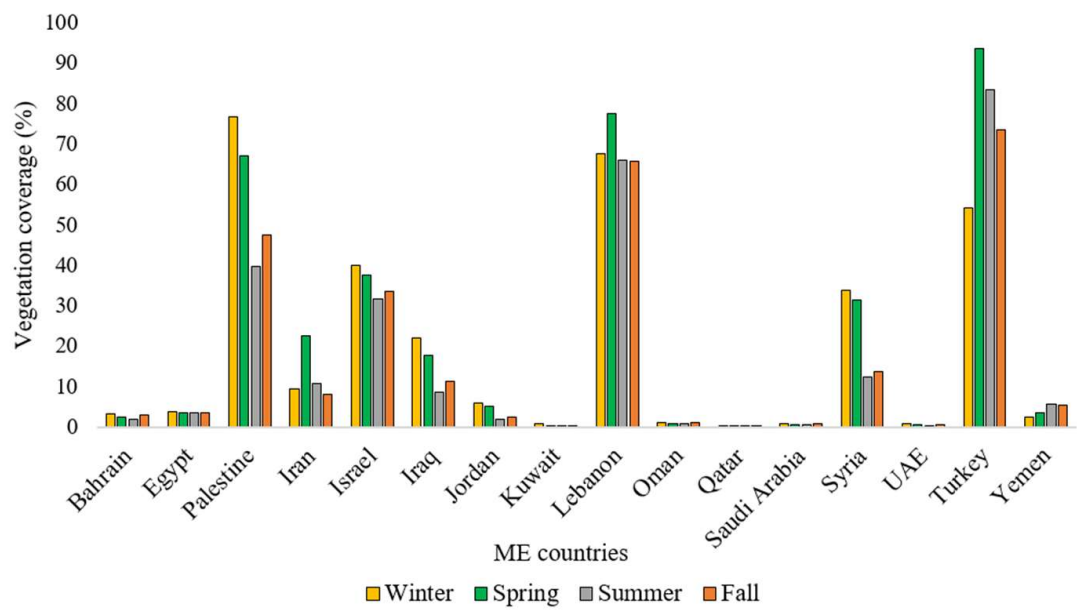

Figure 8. Average vegetation coverage area in the Middle East during 2001-2019. 
Table 3. Seasonal vegetation coverage percentage in Middle East countries during 2001-2019.

\begin{tabular}{cccccc}
\hline Country & Winter (\%) & Spring (\%) & Summer (\%) & Fall (\%) & Average (\%) \\
\hline Bahrain & 3.2 & 2.6 & 1.9 & 3.0 & 2.7 \\
Egypt & 3.8 & 3.6 & 3.6 & 3.6 & 3.7 \\
Palestine & 76.9 & 67.2 & 39.9 & 47.7 & 57.9 \\
Iran & 9.5 & 22.6 & 10.9 & 8.0 & 12.7 \\
Israel & 40.0 & 37.6 & 31.8 & 33.6 & 35.7 \\
Iraq & 22.2 & 17.7 & 8.8 & 11.3 & 15.0 \\
Jordan & 6.0 & 5.1 & 2.0 & 2.6 & 3.9 \\
Kuwait & 1.0 & 0.1 & 0.1 & 0.4 & 0.4 \\
Lebanon & 67.6 & 77.7 & 66.1 & 66.0 & 69.3 \\
Oman & 1.0 & 0.8 & 1.0 & 1.2 & 1.0 \\
Qatar & 0.3 & 0.1 & 0.1 & 0.2 & 0.2 \\
Saudi Arabia & 1.0 & 0.6 & 0.5 & 0.8 & 0.7 \\
Syria & 33.9 & 31.6 & 12.5 & 13.7 & 22.9 \\
UAE & 0.8 & 0.5 & 0.2 & 0.5 & 0.5 \\
Turkey & 54.2 & 93.8 & 83.4 & 73.7 & 76.3 \\
Yemen & 2.4 & 3.5 & 5.6 & 5.6 & 4.3 \\
\hline Average (\%) & $\mathbf{2 0 . 2}$ & $\mathbf{2 2 . 8}$ & $\mathbf{1 6 . 8}$ & $\mathbf{1 7 . 0}$ & $\mathbf{1 9 . 2}$ \\
\hline
\end{tabular}

Figure 9 shows the seasonal average and maximum NDVI of the ME countries from 2001 to 2019. In winter, the maximum NDVI in Egypt, Turkey, and Israel is 0.84, 0.81, and 0.76, respectively, and the NDVI average in Egypt, Israel, and Lebanon is 0.58, 0.48, and 0.41, respectively. The maximum NDVI is the lowest in Bahrain, Oman, and $\operatorname{UAE}(0.39,0.53$, and 0.55, respectively) and the average NDVI is the lowest in UAE, Bahrain, and Yemen $(0.24,0.246$, and 0.249 , respectively). In spring, the NDVI is the highest in Iran, Turkey, and Syria $(0.86,0.85$, and 0.77 , respectively) and the highest NDVI average in Turkey, Egypt, and Lebanon is 0.43, 0.404, and 0.402, respectively. The lowest maximum NDVI was observed in Bahrain, Oman, and Qatar $(0.35,0.43$, and 0.43, respectively) and the lowest average NDVI of $0.231,0.233$, and 0.25 were detected in UAE, Bahrain, and Oman, respectively. In summer, the NDVI the highest in Turkey, Iran, and Syria $(0.92,0.88$, and 0.79, respectively) and the highest NDVI average in Egypt, Turkey, and Iran is 0.49, 0.41, and 0.34, respectively. Moreover, the lowest maximum NDVI was observed in Bahrain, Qatar, and Kuwait $(0.33,0.38$, and 0.42 , respectively) and the lowest average NDVI was detected in Bahrain, UAE, and Palestine $(0.227,0.229$, and 0.24 , respectively). In fall, the maximum NDVI was observed in Turkey, Iran, and Egypt (0.84, 0.82, and 0.76, respectively) and the highest NDVI average in Egypt, Turkey, and Lebanon is $0.45,0.38$, and 0.37 , respectively. The lowest maximum NDVI was observed in Bahrain, Kuwait, and Qatar $(0.37,0.48$, and 0.49 , respectively) and the lowest average NDVI was detected in Bahrain, UAE, and Kuwait (0.23, 0.24, and 0.25, respectively). 

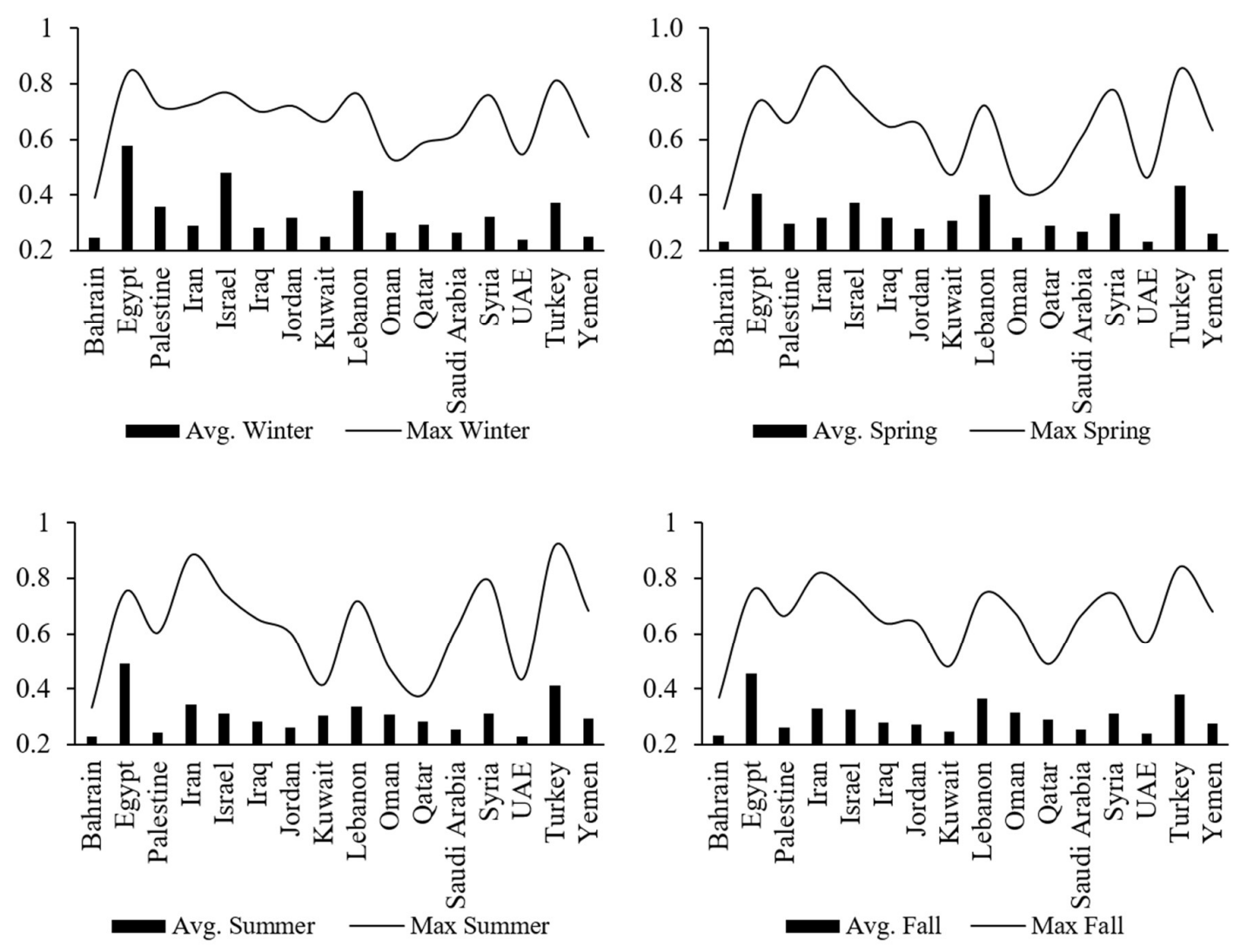

Figure 9. Seasonal average and seasonal maximum Normalized Difference Vegetation Index (NDVI) for each country in the Middle East during 2001-1019.

\subsection{Yearly NDVI dynamics}

Table 4 shows the annual coverage (in percent) and the maximum, average, and majority NDVI for each country in the ME from 2001 to 2019. The majority NDVI is the preferable indicator for studying the variation of the vegetation coverage because other indicators can be sensitive to just one value. For example, the maximum NDVI is sensitive to the highest value; thus, just one value can affect the indicator, whereas the majority refers to the maximum value with the highest frequency in the area. In other words, the majority refers to the highest values with the highest iteration. Therefore, it is not sensitive to one pixel and is representative of the vegetation dynamics in an area.

From 2001 to 2019, the annual coverage significantly increases in Egypt, Iran, Iraq, Kuwait, Lebanon, Oman, Qatar, Saudi Arabia, Turkey, and Yemen. A significant negative NDVI trend was observed in the UAE $(R=-0.72, p$-value $=0.05)$. The trends determined for Bahrain, Palestine, Israel, Jordan, and Syria are insignificant. Overall, the annual coverage in the ME shows a significant positive trend $(R=0.47$, p-value $=0.05)$ from 2001 to 2019. In Egypt and Qatar, the annual coverage continuously increases, with the strongest positive trend in the $\mathrm{ME}(\mathrm{R}=0.99,0.91, \mathrm{p}=0.05)$. Table 4 shows that the vegetation coverage in the UAE decreases from 2001 to 2019.

The maximum NDVI in the ME exhibits a significant positive trend in Bahrain, Palestine, Kuwait, Lebanon, Saudi Arabia, Turkey, and Yemen. An insignificant positive trend can be observed for Egypt, Iran, Israel, Iraq, Jordan, Qatar, Syria, and the UAE. A significant negative trend was detected for Oman $(R=-0.47$, p-value $=0.05)$. The strongest correlations were observed in Palestine and Lebanon, with $\mathrm{R}=0.90$ and 0.88 , respectively, and a p-value of 0.05 . The overall trend of the maximum NDVI in the ME is positive and marginal $(R=0.43, p=0.05)$. 
Table 4. Trends of NDVI factors in the Middle East during 2001-2019.

\begin{tabular}{|c|c|c|c|c|}
\hline Country & $\begin{array}{c}\text { Annual } \\
\text { coverage (\%) }\end{array}$ & $\begin{array}{c}\text { Max } \\
\text { NDVI }\end{array}$ & $\begin{array}{c}\text { Average } \\
\text { NDVI }\end{array}$ & $\begin{array}{c}\text { Majority } \\
\text { NDVI }\end{array}$ \\
\hline Bahrain & 0.37 & $0.69 *$ & -0.27 & -0.36 \\
\hline Egypt & $0.99 *$ & 0.37 & $-0.77^{*}$ & 0.04 \\
\hline Palestine & 0.16 & 0.90 * & $0.47^{*}$ & 0.31 \\
\hline Iran & $0.68 *$ & 0.44 & -0.39 & 0.11 \\
\hline Israel & 0.16 & 0.26 & 0.40 & 0.26 \\
\hline Iraq & $0.49^{*}$ & 0.26 & $0.75 *$ & -0.35 \\
\hline Jordan & 0.16 & 0.36 & 0.27 & -0.09 \\
\hline Kuwait & $0.71 *$ & 0.58 * & $-0.65 *$ & -0.19 \\
\hline Lebanon & $0.63 *$ & $0.88 *$ & 0.56 * & -0.08 \\
\hline Oman & $0.54 *$ & $-0.47^{*}$ & 0.01 & -0.23 \\
\hline Qatar & $0.91 *$ & 0.28 & $-0.64^{*}$ & -0.20 \\
\hline Saudi Arabia & $0.83 *$ & $0.71 *$ & 0.83 * & -0.03 \\
\hline Syria & 0.18 & 0.13 & 0.12 & 0.18 \\
\hline UAE & $-0.72 *$ & 0.36 & $0.64^{*}$ & -0.31 \\
\hline Turkey & $0.75^{*}$ & $0.64 *$ & 0.88 * & $0.54^{*}$ \\
\hline Yemen & $0.63 *$ & $0.50 *$ & $0.76^{*}$ & -0.07 \\
\hline Average & $0.47 *$ & 0.43 & 0.19 & -0.03 \\
\hline
\end{tabular}

The average NDVI in ME countries exhibits a significant positive trend in Palestine, Iraq, Lebanon, Saudi Arabia, UAE, Turkey, and Yemen. The strongest correlations were observed in Turkey and Saudi Arabia ( $R=0.88$ and 0.83 , respectively, and $p=0.05)$. In addition, a significant negative trend was observed in Egypt, Kuwait, and Qatar, with $\mathrm{R}=-0.77,-0.65$, and -0.64, respectively, and a p-value of 0.05. In Oman and Saudi Arabia, the average NDVI shows no trend during the study period.

The majority NDVI in Turkey exhibits a significant positive trend $(\mathrm{R}=0.54, \mathrm{p}$-value $=0.05)$; in other ME countries, the trend is insignificant. An insignificant positive trend was observed in Bahrain, Iraq, Kuwait, Oman, Qatar, and the UAE; in Bahrain, Iraq, and the UAE, the correlation is stronger than in other countries ( $\mathrm{R}=-0.36,-0.35$, and 0.31 , respectively). An insignificant positive trend was observed in Palestine, Iran, Israel, and Syria; in Palestine and Israel, this correlation is stronger than in other countries $(R=0.31$ and 0.26$)$ during 2001-2019.

\section{Discussion}

Water scarcity is one of the most severe issues in the ME. It can directly affect the vegetation coverage in this area. Water scarcity has several reasons including high temperatures, relatively irregular dissemination of rainfall, increasing irrigation water loads, and tourism inflation. Furthermore, climate change likely augments this situation. With respect to long-term trends of vegetation coverage and productivity, government policies play vital roles in this arid and semiarid region. The ME is an arid region. The greenest areas of the region are located in 1) mountainous areas and 2) coastal areas of the Black, Caspian, and Mediterranean seas. The water bodies in the southern regions of the $\mathrm{ME}$ do not have any effect on the increasing vegetation coverage and the role of mountainous areas (elevation) is more important than the distance to the water bodies in these regions of the study area. Therefore, three main elements affect the vegetation cover in the study area: 
1) elevation; 2) distance from the waterbodies in the western and northern regions; and 3) geographical coordinates (latitudes).

The main weather phenomenon in the Persian Gulf, Oman Sea, Indian Ocean, Arab Sea, and the Red Sea is Subtropical High Pressure (STHP). This phenomenon prevents any convectional flows and there is no dense vegetation in the coastal areas of the mentioned water bodies despite the high humidity. The study area is in one of the driest deserts in the world due to the STHP. The region is characterized by very scarce vegetation, which entirely depends on the existence of the mountainous area [72-75]. The northern and western parts of the study area are located in the pathway of the westerlies. The main factors affecting the atmospheric dynamics are westerlies and the large water bodies (Black, Mediterranean, and Caspian seas), which supply the water vapor; therefore, these areas contain the densest vegetation in the ME [76-79].

In Egypt, almost all green places are located in the Nile Delta and along the Nile River, while other parts of the country ( $97 \%)$ are characterized by the desert. The annual vegetation coverage of this country shows the strongest positive trend in the $\mathrm{ME}(\mathrm{R}=0.99$, p-value $=0.05)$. Kuwait and Qatar have similar but weaker trends. The main reasons for this strong positive trend in Egypt are governmental policies, which aim to extend the forest area of the country. Scientists are recuperating wastewater from the city of Ismailia in northern Egypt and are using water to produce fecundate trees. Within less than 20 years, over 200 ha of forests were developed in the desert, which is the main reason for the increase in the annual vegetation coverage in Egypt from 2001 to 2019, which is consistent with Loutfy's findings [80].

Despite the increase in the annual vegetation coverage in Egypt during the study period, the average NDVI is decreasing $(R=-0.77$, p-value $=0.05)$. This is due to the creation of new forest areas by policymakers, which leads to an increase in the annual coverage. The leaf cover of these new forest areas is still low, resulting in low NDVI, and this is the main reason why a decrease in the average NDVI is observed. However, this trend cannot be generalized to other countries. For example, a significant increase both in the annual vegetation coverage and the monthly average NDVI can be observed in Iraq, which includes areas with very sparse vegetation. The monthly average NDVI in this country is $\sim 0.27$ in all seasons and winter is the greenest season. Therefore, when local governments or farmers start to work on bare land, the average NDVI increases.

Turkey is the only country in the ME in which all NDVI indicators are significant and increasing. Therefore, both the vegetation coverage and density increased from 2001 to 2019 in this country. The main reason is the construction of some of the biggest dams in the ME, such as the Atatürk Dam (1995) and Ilisu Dam (2006), which supported the increase in the vegetation coverage in these regions. Our results are consistent with the findings of Özcan et al. [81]. Due to the inundation of the Atatürk Dam Lake, a large area of agricultural fields $\left(\sim 368 \mathrm{~km}^{2}\right)$ has been affected. However, the agricultural fields in the Harran Plain increased by $56.3 \%$ (by $1552 \mathrm{~km}^{2}$ up to $2756 \mathrm{~km}^{2}$ ) because of irrigation during the period 1984-2011 [81].

Because water resources are low and the average annual precipitation is below $100 \mathrm{~mm}$, Saudi Arabia has become the world's poorest country in terms of water. Groundwater, surface water, desalinated seawater, and treated wastewater are the major sources of drinking water [82]. However, during 2001-2019, the annual vegetation coverage and maximum and average NDVI significantly increased in the country. This is due to the significant amount of farming in the northern parts of the country. The farming areas and greenhouses are irrigated using groundwater, and some of them are using desalinated seawater [83]. 

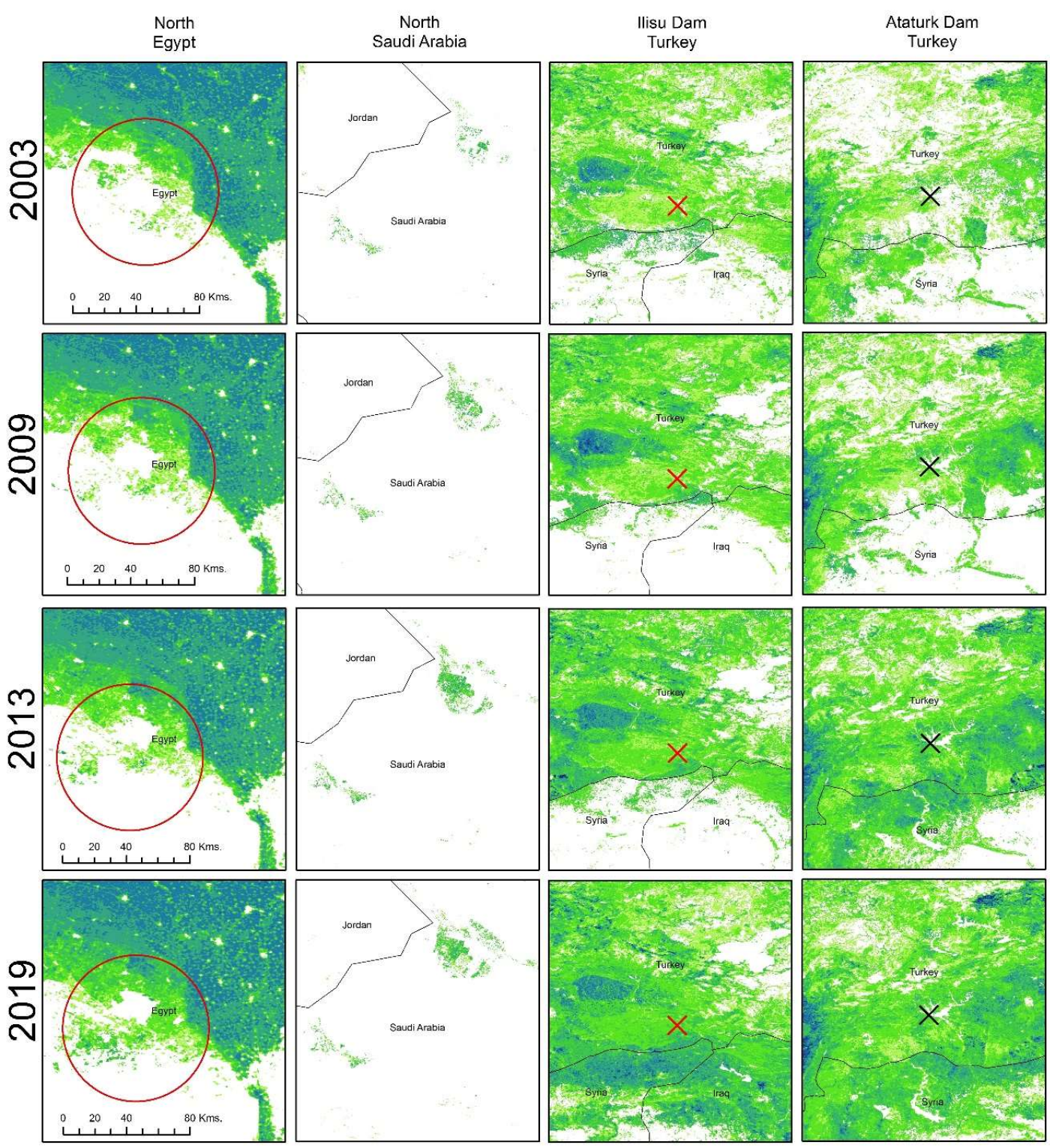

\section{Legend}
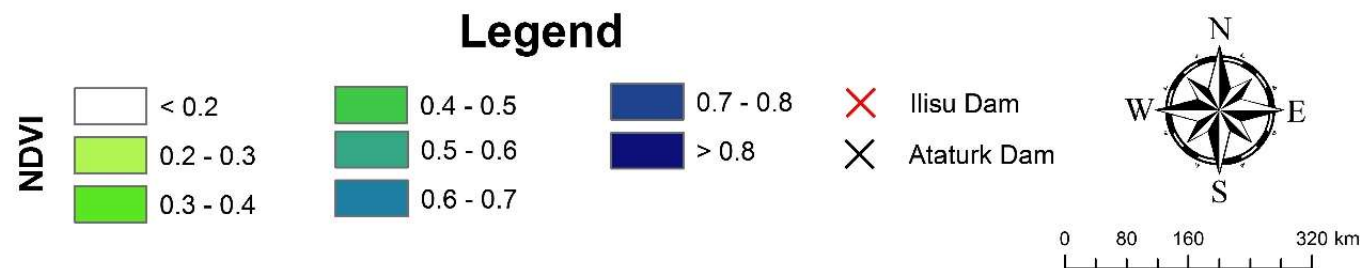

Figure 10. Maps of the NDVI for the selected years (2003, 2009, 2013, and 2019) and areas (south-west part of Nile Delta in northern Egypt, northern Saudi Arabia, and region surrounding the Atatürk and Ilisu dams in southern Turkey) reflecting the progressive impact of anthropopressure.

UAE is a small country in a large desert. During the study period, the annual coverage of this country significantly decreased compared with that of all other countries in the ME; however, the average NDVI significantly increased. It was observed that very sparse vegetation vanished during the study period. Therefore, almost all remaining vegetation near the inhabited areas has been protected and improved, and the average NDVI significantly increased during 2001-2019. 
The increase in the NDVI in the above-mentioned countries can be attributed to anthropopressure and is illustrated in Figure 10. A rapid growth in NDVI can be observed in areas where government policies regarding the irrigation of agricultural fields were established. These policies either include the use of desalinated seawater or groundwater (Nile Delta in northern Egypt or northern Saudi Arabia) or water from lakes that were created by dam construction (Atatürk and Ilisu dams in southern Turkey).

\section{Conclusions}

In this study, the interannual and interseasonal variabilities of the vegetation in the ME were analyzed. The results show that climate inconsistency and drought are common phenomena in the entire region. Areas with steep precipitation gradients and marginal rain-fed agricultural fields are the main areas of interest with respect to the mitigation of drought based on the development of local processes to assess, monitor, and evaluate the vegetation dynamics.

The results reveal that the NDVI in the ME increases from January to late April, indicating that $21 \%$ of the area is covered by vegetation. Starting in May, the vegetation cover decreases and the minimum annual coverage $(14 \%)$ is reached in the warm season by the end of September.

The main GS in the ME starts around January 1 and ends within the first ten days of May. During the study period, the NDVI coverage exhibited a significant positive trend in the study area $(R=0.75$, $\mathrm{p}$-value $=0.05)$. A significant increase $(\mathrm{p}$-value $=0.05)$ was observed in the NDVI category 0.3 to $>0.8$. The ME is becoming greener; the vegetation coverage shows a positive increasing trend in all months. Vegetation covers $\sim 19.2 \%$ of the whole study area. Spring is the greenest season, followed by winter, fall, and summer.

The densest vegetation coverage can be observed in the coastal areas of the Caspian, Black, and Mediterranean seas and along the large rivers. The driest countries in the ME are Qatar, Kuwait, the UAE, and Saudi Arabia.

In winter, the highest maximum NDVI was detected in Egypt, Turkey, and Israel and the highest NDVI average was observed in Egypt, Israel, and Lebanon, with values of 0.58, 0.48, and 0.41, respectively.

In spring, the maximum NDVI is the highest in Iran, Turkey, and Syria and the highest NDVI average was observed in Turkey, Egypt, and Lebanon. In summer, the maximum NDVI is the highest in Turkey, Iran, and Syria and the NDVI average is the highest in Egypt, Turkey, and Iran. In fall, the highest maximum NDVI was observed in Turkey, Iran, and Egypt and the highest NDVI average was detected in Egypt, Turkey, and Lebanon.

The main factors affecting the vegetation coverage in the ME are government policies. These policies can have a positive and continuous effect on the vegetation coverage, as observed in Egypt, Saudi Arabia, Qatar, Kuwait, Iran, and Turkey. However, some of these policies can have negative effects on other countries. For example, the construction of a dam on a river that originates in a certain country and flows to other countries can have a positive effect on the source country and negative effects on the vegetation of countries located downriver. For example, the Kajaki Dam on the Helmand River in Afghanistan harms the vegetation in the Sistan and Baluchestan Province of Iran. The Ilisu Dam, constructed on the Tigris River, harms the vegetation in Iraq and Iran.

Further research should be carried out on ME vegetation dynamics, incorporating historical vegetation dynamics, and their correlations with the atmospheric variability and land-atmosphere interactions in this environmentally sensitive territory.

Author Contributions: I.R. proposed the study. I.R., H.O., H.Z., and Md.M. carried out the data processing and analysis and wrote the manuscript. J.K. and P.B. enhanced the research design, helped with the analysis and interpretation of the results, and helped with writing the manuscript.

Funding: This research was supported by Vedurfelagid, Rannis, and Rannsoknastofa i vedurfraedi. J.K. and P.B. have been partly financed by the Polish National Centre for Research and Development within the framework of the MSINiN project (contract number: BIOSTRATEG3/343547/8/NCBR/2017). 
Conflicts of Interest: The authors declare no conflicts of interest. The funding bodies played no roles in the design of the study; in the collection, analyses, or interpretation of data; in the writing of the manuscript; nor in the decision to publish the results.

\section{References}

1. Anderson, R.G.; Canadell, J.G.; Randerson, J.T.; Jackson, R.B.; Hungate, B.A.; Baldocchi, D.D.; Ban-Weiss, G.A.; Bonan, G.B.; Caldeira, K.; Cao, L. Biophysical considerations in forestry for climate protection. Front. Ecol. Environ 2011, 9, 174-182.

2. Guo, W.; Ni, X.; Jing, D.; Li, S. Spatial-temporal patterns of vegetation dynamics and their relationships to climate variations in Qinghai Lake Basin using MODIS time-series data. J. Geogr. Sci. 2014, 24, 1009-1021.

3. Jackson, R.B.; Randerson, J.T.; Canadell, J.G.; Anderson, R.G.; Avissar, R.; Baldocchi, D.D.; Bonan, G.B.; Caldeira, K.; Diffenbaugh, N.S.; Field, C.B. Protecting climate with forests. Environ. Res. Lett. 2008, 3, 044006.

4. Verbesselt, J.; Hyndman, R.; Newnham, G.; Culvenor, D. Detecting trend and seasonal changes in satellite image time series. Remote Sens. Environ. 2010, 114, 106-115.

5. Cramer, W.; Bondeau, A.; Woodward, F.I.; Prentice, I.C.; Betts, R.A.; Brovkin, V.; Cox, P.M.; Fisher, V.; Foley, J.A.; Friend, A.D. Global response of terrestrial ecosystem structure and function to $\mathrm{CO}_{2}$ and climate change: results from six dynamic global vegetation models. Glob. Chang. Biol. 2001, 7, 357-373.

6. Gaston, K.J. Global patterns in biodiversity. Nature 2000, 405, 220-227.

7. Theurillat, J.-P.; Guisan, A. Potential impact of climate change on vegetation in the European Alps: a review. Clim. Change 2001, 50, 77-109.

8. Wolters, V.; Silver, W.L.; Bignell, D.E.; Coleman, D.C.; Lavelle, P.; Van Der Putten, W.H.; De Ruiter, P.; Rusek, J.; Wall, D.H.; Wardle, D.A. Effects of Global Changes on Above-and Belowground Biodiversity in Terrestrial Ecosystems: Implications for Ecosystem Functioning: We identify the basic types of interaction between vascular plants and soil biota; describe the sensitivity of each type to changes in species composition; and, within this framework, evaluate the potential consequences of global change drivers on ecosystem processes. Bioscience 2000, 50, 1089-1098.

9. Li, X.; Jia, X.; Dong, G. Influence of desertification on vegetation pattern variations in the cold semi-arid grasslands of Qinghai-Tibet Plateau, North-west China. J. Arid Environ. 2006, 64, 505-522.

10. Lucas, R.; Rowlands, A.; Brown, A.; Keyworth, S.; Bunting, P. Rule-based classification of multi-temporal satellite imagery for habitat and agricultural land cover mapping. ISPRS J. Photogramm. Remote Sens. 2007, 62, 165-185.

11. Tong, X.; Wang, K.; Yue, Y.; Brandt, M.; Liu, B.; Zhang, C.; Liao, C.; Fensholt, R. Quantifying the effectiveness of ecological restoration projects on long-term vegetation dynamics in the karst regions of Southwest China. Int. J. Appl. Earth Obs. Geoinf. 2017, 54, 105-113.

12. Xiao, X.; Wang, Y.; Jiang, S.; Ojima, D.S.; Bonham, C.D. Interannual variation in the climate and aboveground biomass of Leymus chinense steppe and Stipa grandis steppe in the Xilin river basin, Inner Mongolia, China. J. Arid Environ. 1995, 31, 283-299.

13. Bradley, B.A.; Mustard, J.F. Comparison of phenology trends by land cover class: a case study in the Great Basin, USA. Glob. Chang. Biol. 2008, 14, 334-346.

14. Frolking, S.; Palace, M.W.; Clark, D.; Chambers, J.Q.; Shugart, H.; Hurtt, G.C. Forest disturbance and recovery: A general review in the context of spaceborne remote sensing of impacts on aboveground biomass and canopy structure. J. Geophys. Res. Biogeosci. 2009, 114, G00E02.

15. Fu, B.; Burgher, I. Riparian vegetation NDVI dynamics and its relationship with climate, surface water and groundwater. J. Arid Environ. 2015, 113, 59-68.

16. Ghafarian Malamiri, H.R.; Rousta, I.; Olafsson, H.; Zare, H.; Zhang, H. Gap-Filling of MODIS Time Series Land Surface Temperature (LST) Products Using Singular Spectrum Analysis (SSA). Atmosphere 2018, 9, 334.

17. Guillevic, P.; Koster, R.; Suarez, M.; Bounoua, L.; Collatz, G.; Los, S.; Mahanama, S. Influence of the interannual variability of vegetation on the surface energy balance-A global sensitivity study. $J$. Hydrometeorol. 2002, 3, 617-629.

18. Höpfner, C.; Scherer, D. Analysis of vegetation and land cover dynamics in north-western Morocco during the last decade using MODIS NDVI time series data. Biogeosciences 2011, 8, 3359-3373. 
19. Ludwig, J.A.; Bastin, G.N.; Chewings, V.H.; Eager, R.W.; Liedloff, A.C. Leakiness: a new index for monitoring the health of arid and semiarid landscapes using remotely sensed vegetation cover and elevation data. Ecol. Indic. 2007, 7, 442-454.

20. Lunetta, R.S.; Knight, J.F.; Ediriwickrema, J.; Lyon, J.G.; Worthy, L.D. Land-cover change detection using multi-temporal MODIS NDVI data. Remote Sens. Environ. 2006, 105, 142-154.

21. Mushore, T.D.; Dube, T.; Manjowe, M.; Gumindoga, W.; Chemura, A.; Rousta, I.; Odindi, J.; Mutanga, O. Remotely sensed retrieval of Local Climate Zones and their linkages to land surface temperature in Harare metropolitan city, Zimbabwe. Urban Clim. 2019, 27, 259-271.

22. Tucker, C.J.; Slayback, D.A.; Pinzon, J.E.; Los, S.O.; Myneni, R.B.; Taylor, M.G. Higher northern latitude normalized difference vegetation index and growing season trends from 1982 to 1999. Int. J. Biometeorol. 2001, 45, 184-190.

23. Wang, J.; Rich, P.M.; Price, K.P. Temporal responses of NDVI to precipitation and temperature in the central Great Plains, USA. Int. J. Remote Sens. 2003, 24, 2345-2364.

24. White, A.B.; Kumar, P.; Tcheng, D. A data mining approach for understanding topographic control on climate-induced inter-annual vegetation variability over the United States. Remote Sens. Environ. 2005, 98, $1-20$.

25. Zhao, B.; Yan, Y.; Guo, H.; He, M.; Gu, Y.; Li, B. Monitoring rapid vegetation succession in estuarine wetland using time series MODIS-based indicators: an application in the Yangtze River Delta area. Ecol. Indic. 2009, 9, 346-356.

26. Justice, C.O.; Vermote, E.; Townshend, J.R.; Defries, R.; Roy, D.P.; Hall, D.K.; Salomonson, V.V.; Privette, J.L.; Riggs, G.; Strahler, A. The Moderate Resolution Imaging Spectroradiometer (MODIS): Land remote sensing for global change research. IEEE Trans. Geosci. Remote Sens. 1998, 36, 1228-1249.

27. Dineshkumar, C.; Nitheshnirmal, S.; Bhardwaj, A.; Priyadarshini, K.N. Phenological Monitoring of Paddy Crop Using Time Series MODIS Data. Proceedings 2019, 24, 19, 1-6.

28. Rousta, I.; Olafsson, H.; Moniruzzaman, M.; Zhang, H.; Liou, Y.-A.; Mushore, T.D.; Gupta, A. Impacts of Drought on Vegetation Assessed by Vegetation Indices and Meteorological Factors in Afghanistan. Remote Sens. 2020, 12, 2433.

29. Fensholt, R.; Sandholt, I.; Rasmussen, M.S. Evaluation of MODIS LAI, fAPAR and the relation between fAPAR and NDVI in a semi-arid environment using in situ measurements. Remote Sens. Environ. 2004, 91, 490-507.

30. Pettorelli, N.; Vik, J.O.; Mysterud, A.; Gaillard, J.-M.; Tucker, C.J.; Stenseth, N.C. Using the satellite-derived NDVI to assess ecological responses to environmental change. Trends Ecol. Evol. 2005, 20, 503-510.

31. Reed, B.C.; Brown, J.F.; VanderZee, D.; Loveland, T.R.; Merchant, J.W.; Ohlen, D.O. Measuring phenological variability from satellite imagery. J. Veg. Sci. 1994, 5, 703-714.

32. Faisal, B.; Rahman, H.; Sharifee, N.H.; Sultana, N.; Islam, M.I.; Ahammad, T. Remotely Sensed Boro Rice Production Forecasting Using MODIS-NDVI: A Bangladesh Perspective. AgriEngineering 2019, 1, 356-375.

33. Rousta, I.; Olafsson, H.; Moniruzzaman, M.; Ardö, J.; Zhang, H.; Mushore, T.D.; Shahin, S.; Azim, S. The 2000-2017 drought risk assessment of the western and southwestern basins in Iran. Model. Earth Syst. Environ. 2020, 6, 1201-1221.

34. Schnur, M.T.; Xie, H.; Wang, X. Estimating root zone soil moisture at distant sites using MODIS NDVI and EVI in a semi-arid region of southwestern USA. Ecol. Inform. 2010, 5, 400-409.

35. Busetto, L.; Meroni, M.; Colombo, R. Combining medium and coarse spatial resolution satellite data to improve the estimation of sub-pixel NDVI time series. Remote Sens. Environ. 2008, 112, 118-131.

36. Sims, N.C.; Colloff, M.J. Remote sensing of vegetation responses to flooding of a semi-arid floodplain: Implications for monitoring ecological effects of environmental flows. Ecol. Indic. 2012, 18, 387-391.

37. Cho, M.A.; Skidmore, A.; Corsi, F.; Van Wieren, S.E.; Sobhan, I. Estimation of green grass/herb biomass from airborne hyperspectral imagery using spectral indices and partial least squares regression. Int. J. Appl. Earth Obs. Geoinf. 2007, 9, 414-424.

38. Rouse, J.; Haas, R.; Schell, J.; Deering, D. Monitoring vegetation systems in the Great Plains with ERTS. NASA special publication 1974, 351, 309.

39. Goward, S.N.; Dye, D.G. Evaluating North American net primary productivity with satellite observations. Adv. Space Res. 1987, 7, 165-174.

40. Nielsen, T.T.; Adriansen, H.J.L.D. Government policies and land degradation in the Middle East. Land Degrad. Dev. 2005, 16, 151-161. 
41. Barbosa, H.; Huete, A.; Baethgen, W. A 20-year study of NDVI variability over the Northeast Region of Brazil. J. Arid Environ. 2006, 67, 288-307.

42. Gaughan, A.E.; Stevens, F.R.; Gibbes, C.; Southworth, J.; Binford, M.W. Linking vegetation response to seasonal precipitation in the Okavango-Kwando-Zambezi catchment of southern Africa. Int. J. Remote Sens. 2012, 33, 6783-6804.

43. Ji, L.; Peters, A.J. Assessing vegetation response to drought in the northern Great Plains using vegetation and drought indices. Remote Sens. Environ. 2003, 87, 85-98.

44. Zaitchik, B.F.; Evans, J.P.; Geerken, R.A.; Smith, R.B.J.J.o.C. Climate and vegetation in the Middle East: Interannual variability and drought feedbacks. J. Climate 2007, 20, 3924-3941.

45. Bagherzadeh, A.; Hoseini, A.V.; Totmaj, L.H. The effects of climate change on normalized difference vegetation index (NDVI) in the Northeast of Iran Model. Earth Syst. Environ. 2020, 6, 671-683.

46. Cai, H.; Yang, X.; Wang, K.; Xiao, L. Is forest restoration in the southwest China Karst promoted mainly by climate change or human-induced factors? Remote Sens. 2014, 6, 9895-9910.

47. Chuai, X.; Huang, X.; Wang, W.; Bao, G. NDVI, temperature and precipitation changes and their relationships with different vegetation types during 1998-2007 in Inner Mongolia, China. Int. J. Climatol. 2013, 33, 1696-1706.

48. Wang, J.; Meng, J.; Cai, Y. Assessing vegetation dynamics impacted by climate change in the southwestern karst region of China with AVHRR NDVI and AVHRR NPP time-series. Environ. Geol. 2008, 54, 1185-1195.

49. Archer, E.R. Beyond the "climate versus grazing" impasse: using remote sensing to investigate the effects of grazing system choice on vegetation cover in the eastern Karoo. J. Arid Environ. 2004, 57, 381-408.

50. Herrmann, S.M.; Anyamba, A.; Tucker, C.J. Recent trends in vegetation dynamics in the African Sahel and their relationship to climate. Glob. Environ. Change 2005, 15, 394-404.

51. Pinzon, J.E.; Tucker, C.J. A non-stationary 1981-2012 AVHRR NDVI3g time series. Remote Sens. 2014, 6, 6929-6960.

52. Running, S.W.; Nemani, R.R. Relating seasonal patterns of the AVHRR vegetation index to simulated photosynthesis and transpiration of forests in different climates. Remote Sens. Environ. 1988, 24, 347-367.

53. Evans, J.; Geerken, R. Discrimination between climate and human-induced dryland degradation. J. Arid Environ. 2004, 57, 535-554.

54. Fisher, L. Presidential war power, 3rd ed.; Publisher: University Press of Kansas, 2013

55. Budhwar, P.; Mellahi, K. Introduction: human resource management in the Middle East. Int. J. Hum. Resour. Manag. 2007, 18, 2-10.

56. Budhwar, P.; Mellahi, K. HRM in the Middle East. In Handbook of Research on Comparative Human Resource Management, 2nd ed.; Publisher: Edward Elgar Publishing, 2018.

57. Zandbergen, P. Applications of shuttle radar topography mission elevation data. Geogr. Compass 2008, 2, 1404-1431.

58. Dutta, D.; Kundu, A.; Patel, N.; Saha, S.; Siddiqui, A. Assessment of agricultural drought in Rajasthan (India) using remote sensing derived Vegetation Condition Index (VCI) and Standardized Precipitation Index (SPI). Egypt. J. Remote. Sens. Space Sci. 2015, 18, 53-63.

59. Gitelson, A.A.; Viña, A.; Arkebauer, T.J.; Rundquist, D.C.; Keydan, G.; Leavitt, B. Remote estimation of leaf area index and green leaf biomass in maize canopies. Geophys. Res. Lett. 2003, 30, 1248.

60. Tarpley, J.; Schneider, S.; Money, R. Global vegetation indices from the NOAA-7 meteorological satellite. J. Clim. Appl. Meteorol. 1984, 23, 491-494.

61. Thenkabail, P.S.; Gamage, M. The use of remote sensing data for drought assessment and monitoring in Southwest Asia; Publisher: International Water Management Institute, 2004.

62. Geerken, R.; Zaitchik, B.; Evans, J. Classifying rangeland vegetation type and coverage from NDVI time series using Fourier Filtered Cycle Similarity. Int. J. Remote Sens. 2005, 26, 5535-5554.

63. Martínez, B.; Gilabert, M. Vegetation dynamics from NDVI time series analysis using the wavelet transform. Remote Sens. Environ. 2009, 113, 1823-1842.

64. Moulin, S.; Kergoat, L.; Viovy, N.; Dedieu, G. Global-scale assessment of vegetation phenology using NOAA/AVHRR satellite measurements. J. Climate 1997, 10, 1154-1170.

65. Running, S.W.; Loveland, T.R.; Pierce, L.L.; Nemani, R.R.; Hunt Jr, E. A remote sensing based vegetation classification logic for global land cover analysis. Remote Sens. Environ. 1995, 51, 39-48.

66. Townshend, J.R.; Justice, C. Analysis of the dynamics of African vegetation using the normalized difference vegetation index. Int. J. Remote Sens. 1986, 7, 1435-1445. 
67. Goward, S.N.; Markham, B.; Dye, D.G.; Dulaney, W.; Yang, J. Normalized difference vegetation index measurements from the Advanced Very High Resolution Radiometer. Remote Sens. Environ. 1991, 35, $257-$ 277.

68. Didan, K. 2015. MOD13Q1 MODIS/Terra vegetation indices 16-day L3 global 250m SIN grid V006. NASA EOSDIS Land Processes DAAC.

69. Patel, N.; Chopra, P.; Dadhwal, V. Analyzing spatial patterns of meteorological drought using standardized precipitation index. Met. Apps 2007, 14, 329-336.

70. Raja, R.; Nayak, A.; Panda, B.; Lal, B.; Tripathi, R.; Shahid, M.; Kumar, A.; Mohanty, S.; Samal, P.; Gautam, P. Monitoring of meteorological drought and its impact on rice (Oryza sativa L.) productivity in Odisha using standardized precipitation index. Arch. Agron. Soil Sci. 2014, 60, 1701-1715.

71. Song, K.-B.; Baek, Y.-S.; Hong, D.H.; Jang, G. Short-term load forecasting for the holidays using fuzzy linear regression method. IEEE Trans. Power Syst. 2005, 20, 96-101.

72. Li, J.; Chou, J. Dynamical analysis on splitting of subtropical high-pressure zone. Chin. Sci. Bull. 1998, 43, 1285-1289.

73. Najafi, M.S.; Sarraf, B.; Zarrin, A.; Rasouli, A. Climatology of atmospheric circulation patterns of Arabian dust in western Iran. Environ. Monit. Assess. 2017, 189, 473.

74. Rousta, I.; Doostkamian, M.; Haghighi, E.; Mirzakhani, B. Statistical-synoptic analysis of the atmosphere thickness pattern of iran's pervasive frosts. Climate 2016, 4, 41.

75. Rousta, I.; Karampour, M.; Doostkamian, M.; Olafsson, H.; Zhang, H.; Mushore, T.D.; Karimvandi, A.S.; Vargas, E.R.M. Synoptic-dynamic analysis of extreme precipitation in Karoun River Basin, Iran. Arab. J. Geosci. 2020, 13, 1-16.

76. Rousta, I.; Nasserzadeh, M.H.; Jalali, M.; Haghighi, E.; Ólafsson, H.; Ashrafi, S.; Doostkamian, M.; Ghasemi, A. Decadal spatial-temporal variations in the spatial pattern of anomalies of extreme precipitation thresholds (Case Study: Northwest Iran). Atmosphere 2017, 8, 135.

77. Rousta, I.; Javadizadeh, F.; Dargahian, F.; Olafsson, H.; Shiri-Karimvandi, A.; Vahedinejad, S.H.; Doostkamian, M.; Monroy Vargas, E.R.; Asadolahi, A. Investigation of vorticity during prevalent winter precipitation in Iran. Adv. Meteorol. 2018, 6941501, 1-13.

78. Rousta, I.; Doostkamian, M.; Ólafsson, H.; Zhang, H.; Vahedinejad, S.H.; Sarif, M.O.; Monroy Vargas, E.R. Analyzing the fluctuations of atmospheric precipitable water in Iran during various periods based on the retrieving technique of NCEP/NCAR. Open Atmospheric Sci. J. 2018, 12, 48-57.

79. Rousta, I.; Doostkamian, M.; Olafsson, H.; Ghafarian-Malamiri, H.; Zhang, H.; Taherian, A.; Sarif, M.; Gupta, R.; Monroy-Vargas, E. On the relationship between the $500 \mathrm{hPa}$ height fluctuations and the atmosphere thickness over Iran and the Middle East. Tethys 2019, 16, 3-14.

80. Loutfy, N.M. Reuse of Wastewater in Mediterranean Region, Egyptian Experience. In: Waste Water Treatment and Reuse in the Mediterranean Region, Barceló, D., Petrovic, M., Eds. Springer Berlin Heidelberg: Berlin, Heidelberg, 2011, pp. 183-213.

81. Özcan, O.; Bookhagen, B.; Musaoğlu, N. Impact of the Atatürk dam lake on agro-meteorological aspects of the southeastern Anatolia region, turkey. J. Indian Soc. Remote. Sens. 2018, 46, 471-481.

82. Abdel-Satar, A.M.; Al-Khabbas, M.H.; Alahmad, W.R.; Yousef, W.M.; Alsomadi, R.H.; Iqbal, T. Quality assessment of groundwater and agricultural soil in Hail region, Saudi Arabia. Egypt. J. Aquat. Res. 2017, 43, 55-64.

83. Fiaz, S.; Noor, M.A.; Aldosri, F.O. Achieving food security in the Kingdom of Saudi Arabia through innovation: Potential role of agricultural extension. J. Saudi Soc. Agric. Sci. 2018, 17, 365-375. 